\title{
Disclosure: Damned If You Do, Damned If You Don't
}

\author{
Renee Bittoun \\ Adjunct Associate Professor, Clinical School, Smoking Cessation Unit, Faculty of Medicine, University of Sydney \\ Director Smokers Clinics, S W Sydney Area Health Service \\ Editor in Chief, The Journal of Smoking Cessation \\ President, AASCP (Australian Association of Smoking Cessation Professionals)
}

Smoking cessation - as important as it is to us in the field, it is not a very sexy subject to grant and funding bodies of any persuasion. Finding funds to pay staff, continue research, teach and develop new ideas is costly and we compete with children with cancer, AIDS, the ravages of diseases in the Third World, etc etc. We are not a big priority in the scheme of things, however well we argue a case for funding on the basis of immense public health benefits. Therefore funding can often come by necessity from sources such as pharmaceutical companies.

We have been in the era of full disclosure of funding for many decades now. It is unacceptable that research is published without the authors and researchers acknowledging their source of funding so as to be, and to be seen to be, publicly open about any perceived bias or 'conflict of interest' that may be overt or covert in their work. In doing this, the scientific community accepts the honesty and integrity of the authors and trusts, when they state that their funding source in no way influenced the content and outcome of their work, and that the content is their independent responsibility.

There have been recent arguments suggesting that public trust can be manipulated as disclosure is voluntary and subject to interpretation (Lee, 2008) and others suggesting that restrictions are so severe that many researchers and clinicians would, among other knowledge-based initiatives, simply be unable to travel to conferences or receive adequate training and benefits of research that have been made in their field (Stossel, 2008).

On one occasion recently this author wrote a report that received considerable favourable public comment (Bittoun, 2007). The report was funded as an 'unrestricted educational grants' with no editorial input or 'ghost writing' by a major pharmaceutical company. Despite, and because of, full disclosure of this fact, some lay press and certain colleagues insinuated that the content of these types of reports are biased due to the funding of the work by a pharmaceutical company. Explicit disclosure of the fact that the funding body had no content nor outcome control did not preclude derision of the material. Had the disclosure not been forthcoming however, the bias label would have been even more severe and the reputation and credibility of this author would have been in disrepute.

I, as most professionals do, have a foremost interest in the health and wellbeing of our patients. So how do we advance in this precarious area the need for funds in the real world and disclosure of those funds without compromising credibility? Disclosure, I believe, should be transparent and full; hence I declare at the end of my articles, rather than list details of all honoraria, hospitalities, travel funding, fees for expert opinions and project grants that I have received over the decades, that 'I take money from anyone (except the tobacco companies, who don't offer anyway)' and hope that this absolves me from bias towards any one particular manufacturer or group and I therefore have no competing or conflicting interests.

\section{References}

Lee, K. (2008). Has the hunt for conflicts of interest gone too far? No. British Medical Journal, 336, 477.

Stossel, T.P. (2008). Has the hunt for conflicts of interest gone too far? Yes. British Medical Journal, 336, 476.

Bittoun, R. (2007). A decade of over-the-counter therapeutic nicotine in Australia (Brain and Mind Research Institute Monograph, May, 2007). 